\title{
microRNAs, an active and versatile group in cancers
}

\author{
Jeffrey Liu ${ }^{1} \dagger$, Min Zheng ${ }^{2} \dagger$, Ya-ling Tang ${ }^{3}$, Xin-hua Liang ${ }^{2,3 *}$, Qin Yang ${ }^{2,4 *}$ \\ ${ }^{1}$ Department of Biological Sciences, University of Delaware, Nowak DE 19716, USA; ${ }^{2}$ State Key Laboratory of Oral \\ Diseases, Sichuan University, Chengdu 610041, China; ${ }^{3}$ Department of Oral and Maxillofacial Surgery, West China \\ School of Stomatology, Sichuan University, Chengdu 610041, China; ${ }^{4}$ Cancer Biology Division, School of Medicine, \\ Washington University, St. Louis MO 63108, USA
}

microRNAs (miRNAs) are a class of non-coding RNAs that function as endogenous triggers of the RNA interference pathway. Studies have shown that thousands of human protein-coding genes are regulated by miRNAs, indicating that miRNAs are master regulators of many important biological processes, such as cancer development. miRNAs frequently have deregulated expression in many types of human cancers, and play critical roles in tumorigenesis, which functions either as tumor suppressors or as oncogenes. Recent studies have shown that miRNAs are highly related with cancer progression, including initiating, growth, apoptosis, invasion, and metastasis. Furthermore, miRNAs are shown to be responsible for the cancer-related inflammation, anti-cancer drug resistance, and regulation of cancer stem cells. Therefore, miRNAs have generated great interest as a novel strategy in cancer diagnosis and therapy. Here we review the versatile roles of miRNAs in cancers and their potential applications for diagnosis, prognosis, and treatment as biomarkers.

Keywords: microRNAs; cancer; epithelial-mesenchymal transition; inflammation; cancer stem cells; drug resistance

International Journal of Oral Science (2011) 3: 165-175. doi: 10.4248/IJOS11063

\section{Introduction}

microRNAs (miRNAs), which negatively regulate gene expression at the post-transcriptional and/or translational level, are short non-coding RNAs 19-25 nucleotides in length, first discovered in Caenorhabditis elegans to control developmental timing [1-3]. Mature miRNAs are formed from longer primary transcripts by two sequential processing steps mediated by a nuclear (Drosha) and a cytoplasmic (Dicer) RNase III endonulease [4-5]. In most animals, miRNAs direct gene regulation at the level of translation. They can down-regulate gene expression either by degradation of messenger RNA (mRNA)

\footnotetext{
$\dagger$ These authors contributed equally to this work. *Correspondence: Xin-hua Liang and Qin Yang Tel: 862885501440 (Liang) Tel: 001314747 5445; Fax: 0013143629790 (Yang) E-mail: 1xh88866@yahoo.com.cn (Liang); qyang@wustl.edu (Yang) Received 15 June 2011; Accepted 8 July 2011
}

through the RNA interference (RNAi) pathway or by inhibiting protein translation [6]. To date, over 1000 miRNAs have been identified in animal genomes through cloning and bioinformatics approaches. Although the biological roles of only a small fraction of identified miRNAs have been elucidated, in mammals, these miRNAs regulate processes essential to cell growth, embryogenesis, stem cell maintenance, hematopoietic cell differentiation, and brain development [7-11]. Since Croce's research group first reported the link between the abnormal expression of miRNAs and cancer in 2002 [12], more and more studies have shown that many miRNAs take part in the progressions of various cancers, including tumor growth, differentiation, adhesion, apoptosis, invasion, and metastasis [13-15]. Cancer is ultimately a consequence of disordered gene expression. miRNA profiling experiments have revealed that many miRNAs are abnormally expressed in clinical cancer samples. In addition, in in vitro and in vivo models, these abnormal expressions have been pointed out to be closely related to various 
biological behaviors of cancers [16-17]. Thus, alterations of miRNAs expression may promote tumor formation by modulating the functional expression of critical genes involved in tumor development and progression [18]. Here we present the progress of miRNAs in cancers and prospect the great potential of miRNAs in cancer diagnosis and therapy in the future.

\section{Tumorigenesis}

miRNAs were reported to be involved in tumorigenesis by targeting tumor suppressor genes or oncogenes directly or indirectly. Because miRNAs are negative regulators of gene expression, the changes of the expression level of these miRNAs can be tumorigenic if they target mRNAs from a tumor suppressor gene, as well as an oncogene. For example, miR-373 was identified as an oncogene that cooperates with Ras in oncogenic transformation by a suppressing signaling through the p53 pathways [19]; miR-31 was found to directly target tumor suppressor genes, large tumor suppressor 2 (LATS2) and protein phosphatase $2 \mathrm{~A}(\mathrm{PP} 2 \mathrm{~A})$ regulatory subunit $\mathrm{B}$ alpha isoform, and repress lung cancer cell growth and tumorigenicity independently and substantially [20]; miR-183, as an oncogene by targeting early growth response 1 (EGR1) and phosphatase and tensin homolog (PTEN), was significantly overexpressed in synovial sarcoma, rhabdomyosarcoma, and colon cancer cell lines, and promoting the tumor cell migration [21]; miR-93, one of the miRNAs within the miR-106b-25 cluster, was able to promote tumor growth and angiogenesis by targeting integrin- $\beta 8$ which was associated with cell death in tumor mass in vivo [22]; Another well-characterized example is the miR-17-92 cluster which is transcriptionally activated by the oncogene c-Myc. They are susceptibility gene at the chr13q13 amplicon and reported to have the causal role in cancer. In a mouse model for lymphoma, co-expression of miR-17-19b, a truncated portion of miR-17-92, strongly accelerated lymphomagenesis [23]; miR-17-5p and miR-20a, two of the miRNAs in the miR-17-92 cluster, could repress the translation of E2F1, a protein that is increased by c-Myc and enhance both cell cycle progression and apoptosis [24-25]. Medina et al. [26] showed that overexpression of miR-21 led to a pre-B malignant lymphoid-like phenotype in vivo. When miR-21 was inactivated, the tumors regressed completely in a few days, partly as a result of apoptosis. Their results supported efforts to treat human cancers through pharmacological inactivation of miRNAs such as miR-21. This conclusion was also confirmed in breast cancer, colon cancer, pancreas cancer, lung cancer, prostate cancer, liver cancer, stomach cancer, and oral squamous cell carcinoma (OSCC) [2732]. Evidence above showed that these tiny non-coding RNAs were playing important roles in the malignant progression of tumors.

\section{Tumor suppressor}

miRNAs have been implicated as tumor suppressor genes. Typical examples are miR-15a and miR-16, which are down-regulated in $68 \%$ of chronic lymphocytic leukemia (CLL). Since these two miRNAs can negatively regulate the expression of the anti-apoptotic factor BCL2, their down-regulation could result in higher BCL2 protein level and anti-apoptotic activity [33-34]. Let-7/miR-98 family is another example for down-regulation of miRNAs that target a number of well-known oncogenes. The roles of let-7 and miR-98 as suppressors in lung cancer were supported by experiments showing that they negatively regulate the expression of the Ras and Myc oncogenes [35-36]. miR-330 was reported to have the suppression roles by negatively regulating E2F 1 and inducing apoptosis through E2F1-mediated suppression of Akt phosphorylation in human prostate cancer cell lines PC-3 [37]. A similar situation was also applied to miR-34a, which was reported to directly target E2F3 and significantly reduced the level of E2F3 protein (a protein transcriptional inducer of cell-cycle progression), acting as a potential tumor suppressor by inducing apoptosis. miR-34a also participated in the regulation of tumor cell scattering, migration, and invasion via down-regulation of c-Met and its downstream signaling cascades [38]. In general, the genomic alterations, particularly tumor suppressor genes amplification or oncogene deletion, can be a major mechanism of inactivation of the tumor suppression function of miRNAs.

Interestingly, recent estimates suggested that as many as $50 \%$ of all nucleotides were transcribed and only $2 \%$ of nucleotides reside in known exons. Moreover, more than half of such transcripts are non-polyadenylated. These RNAs would be invisible to many analyses because the first step is often reverse transcription from the "canonical" polyA tail. And miRNAs are one major group of these hidden RNAs. It is remarkable, because these findings raise the possibility that many miRNAs as oncogenes or suppressors remain to be discovered [39-40].

\section{Invasion and metastasis}

Invasion and metastasis are responsible for $>90 \%$ of cancer-related mortality. As tumors progress with increased malignancy, cells within them develop the ability to invade into surrounding normal tissues and through 
tissue boundaries to form new growths (metastases) at sites distinct from the primary tumor. The molecular mechanisms involved in this process are associated with cell-cell and cell-matrix adhesion, with the degradation of extracellular matrix, and with the initiation and maintenance of early growth at the new site [41-42].

Epithelial-mesenchymal transition (EMT), mainly characterized by E-cadherin degradation, is an important event in invasion and metastasis. E-cadherin, which is encoded by E-cadherin gene (CDH1) and regulated by Snail, Slug, Zeb1, Zeb2, Klf8, Twist1 and Twist2, is a well-known molecule witch maintains the cell-to-cell junctions in epithelial cells [43-44]. Its aberrant expression has been implicated in cancer progression and metastasis [45-46]. miR-373 was considered to have an effective role in E-cadherin targeting. It has been confirmed that the transfection of miR-373 and its precursor hairpin RNA into PC-3 cells readily induced E-cadherin expression. Together with miR-520c, they are considered to be metastasis-promoting miRNAs by direct suppression of CD44 which is consistently reduced in metastatic breast, colon and prostate cancers [47-50].

In breast cancer cells, both miR-10b and -9 are important participants of invasion and metastasis. Homeobox D10 (HOXD10) is a validated target of miR-10b. Ectopic expression of miR-10b has consistently led to the downregulation of HOXD10 expression, and in turn, the induction of RhoC expression. Importantly, either overexpression of HOXD10 or knockdown of RhoC almost completely reversed miR-10b-induced migration and invasion in vitro [51]. It has been shown that miR-9 could directly target $\mathrm{CDH} 1$, the E-cadherin encoding mRNA, leading to increased cell motility and invasiveness [52]. miR-21 was found up-regulated in many solid tumors. When anti-sense oligo against miR-21 was introduced into metastatic cancer cells, their metastatic ability was inhibited, as gauged by a tail-vein metastasis assay and a chick-embryo chorioallantoic-membrane metastasis assay. With further study, it was found that miR-21 could target phosphatase and tensin homolog (PTEN), tumor suppressor gene tropomyosin 1 (TPM1), and programmed cell death 4 (PDCD4), to promote the metastasis of cancers [53-57]. Meanwhile, some miRNAs play a role in inhibiting tumor invasion and metastasis. The let-7 miRNA family of tumor suppressors is downregulated in a variety of tumors. This family of miRNAs has been identified as the silencer of the Ras and HMGA2 oncogenes which promote tumor metastasis [36, 58-60]. The miR-200 family, organized as two clusters in the genome, were expressed during EMT and able to hinder EMT by enhancing E-cadherin transcriptional expression through directly targeting Zeb1 and
Zeb2 [61-63]. Martello have shown that high levels of miR-103/-107 were associated with metastasis and poor outcome in human breast cancer. At the cellular level, a key event fostered by miR-103/-107 was the induction of EMT, attained by down-regulating miR-200 levels [64]. Hedgehog signaling cascade cross-talks with Wnt, epidermal growth factor (EGF)/fibroblast growth factor (FGF), and tumor growth factor- $\beta$ (TGF- $\beta /$ Activin/Nodal/ bone morphogenetic protein (BMP) signaling cascades, which are implicated in epithelial-mesenchymal transition (EMT) through E-cadherin repression [65-67]. It was reported that TGF- $\beta$ could down-regulate the expression of human miR-141, $-200 \mathrm{a} / \mathrm{b} / \mathrm{c},-205$, and -429 , which in turn down-regulate Zeb1 and Zeb2. It is noteworthy that these miRNAs may play important roles in EMT as participants in the Hedgehog signaling cascade [68].

Angiogenesis is another important mechanism in cancer invasion and metastasis. It frequently happens in various tumors and is highly related with invasion, metastasis and poor outcome [69]. Early studies have indicated the contribution of specific miRNAs (e.g. miR-21, -155, and 126) to vascular diseases [70]. At present, miR-126 is widely accepted as an important factor for angiogenesis. Two groups published their investigations back-to-back that miR-126 could regulate the response of endothelial cells to vascular endothelial growth factor (VEGF), and regulate vascular integrity and angiogenesis in vivo [71-72]. Nicoli et al. [73] reported that zinc finger transcription factor Klf2a induced the expression of miR-126 leading to the activation of the VEGF signaling pathway. Their work described a novel genetic mechanism in which a miRNA facilitated the integration of a physiological stimulus with growth factor signaling in endothelial cells to guide angiogenesis. Epidermal growth factor-like domain 7 (EGFL7) was described as a novel endothelial cell-derived factor involved in the blood vessel formation. Fish and colleagues described the transcriptional regulation of EGFL 7 in human endothelial cells by miR-126 [71]. Sun et al. [74] reported that EGFL 7 was a direct target of miR-126 in lung cancer cells and hinted that this could be at least partly explain the observed effect of miR-126 on tumorigenesis. Taken together, these results demonstrated that miR-126 and EGFL7 may share a tightly regulated function in tumor vessel formation. Except the miRNAs mentioned above, miR-17/-20, -31 , and -335 have all been shown to have inhibitory roles in tumor invasion and metastasis as demonstrated in recent studies [75-76].

\section{miRNAs and cancer-related inflammation}

Chronic inflammation is a major cause of cancer. 
Epidemiologic and clinical studies show that approximately $25 \%$ of all human cancers in adults result from chronic inflammation. The oncogenic mechanisms in chronic inflammation are complicated and not fully revealed. Some studies have suggested that induced epigenetic changes and genomic instability were involved in inflammation-induced carcinogenesis. Several transcription factors and key inflammation mediators, such as tumor necrosis factor- $\alpha$ (TNF- $\alpha)$, cyclooxygenase-2 (COX-2), cytokines, hypoxia inducible factor- $1 \alpha$ (HIF-1 $\alpha)$, and nuclear factor- $\kappa \mathrm{B}(\mathrm{NF}-\kappa \mathrm{B})$, have been identified as playing important roles inflammation-induced cancers [77-79]. miRNAs have emerged as a critical regulatory factor in the mammalian immune system. Genetic ablation of the miRNA machinery, as well as loss or deregulation of certain individual miRNAs, severely compromises immune response leading to immune disorders like autoimmunity and cancer [80].

miR-146a is one of the first miRNAs identified to be involved in the regulation of immune function. Lipopolysaccharide (LPS)-induced induction of miR-146a was observed in several other cell lines of myeloid origin, but not in B cell lines, suggesting the LPSinduced regulation of miR-146a is cell-type specific. In addition to the effect on Toll-like receptor (TLR) ligands, miR-146a was induced by TNF- $\alpha$ and interleukin (IL)$1 \beta$ in an NF- $\kappa B$ dependent manner [81-82]. miR-21 is one of the most abundant miRNAs in $\mathrm{T}$ cells in the immune system, indicating that it is critical for $\mathrm{T}$ cell homeostasis [83]. In the expression profiling studies during the innate immune response to aerosolized LPS in the mouse lung, miR-21 was found to be involved in the inflammatory responses [84]. Recent research has shown that miR-21, expressed by inflammatory leukocytes, was the most highly induced miRNA in an IL-13-induced asthma mode. One potential target for miR-21 is IL-12p35, a subunit of IL-12, a key cytokine from macrophages and dendritic cells involved in adaptive immune responses [85]. Schetter et al. [86] examined the expression of 23 inflammatory genes in colon adenocarcinomas and adjacent noncancerous tissues from 196 patients. The results showed that miR-21 was functionally associated with IL-6, -8, -10, -12a and nitric oxide synthase $2 \mathrm{a}$ (NOS2a), suggesting that miR-21 expression was associated with cancer-specific mortality and cancer-related inflammation. These results imply that miR-21 might contribute to the inflammationinduced cancers, at least part, by modulating cytokine responses. miR-155 is regarded as a multifunctional miRNA. Besides acting as an important oncogene, it plays essential roles in both $\mathrm{B}$ and $\mathrm{T}$ cell response identified by two independent groups [87-89]. Similar to
miR-146, miR-155 is regulated by LPS in mouse macrophages. It is also regulated by virally relevant stimuli, such as the synthetic TLR3 ligand poly and by antiviral response cytokines (interferin (IFN)- $\beta,-\gamma$ ), suggesting that miR-155 is a component of the innate immune response [81, 90-91]. Overexpression of miR155 also caused the repression of tumor through targeting p53-induced nuclear protein 1, a pro-apoptotic gene downstream of p53 signaling, suggesting that miR-155 has a pro-tumorigenic function via regulation of inflammation-induced carcinogenesis [92].

miR-17-92 cluster encodes six miRNAs (miR-17, $-18 a,-19 a,-19 b-1,-20 a$, and -92-1) in the human genome. Studies on mouse models have implicated the importance of miR-17-92 cluster in B cell development and $\mathrm{T}$ cell function. In addition, in vivo studies indicate a role for these miRNAs in monocytic development [93-95]. These findings suggest that there might be a potential link between the expression of miR-17-92 cluster and immune system. However, the exact roles of miR-17-92 in inflammation need further investigations. Iliopoulos et al. [96] found that let-7 directly inhibited IL6 expression, resulting in higher levels of IL6 than achieved by NF- $\kappa \mathrm{B}$ activation in several cancer cell lines. This result suggests that let-7 might be important to the cancer-related inflammation. Except the miRNAs described above, many other miRNAs, such as miR-9, miR-101, -192, and -203 , have been also associated with inflammatory diseases or immune responses [97-102].

\section{miRNAs and cancer stem cells}

Cancer stem cell (CSC) model in tumorigenesis proposes that a small fraction of cells in a tumor has properties of stem cells, being responsible for initiating and maintaining the tumor. miRNAs have been found specially expressing in CSCs and controlling their self-renewal and differentiation through regulating the expression of certain key genes [103-106]. Yu et al. [107] found that let-7 regulated multiple stem cell-like properties of breast tumor-initiating cells (BT-ICs) by silencing Harvey rat sarcoma virus oncogene or high mobility group AThook 2 (HMGA2). Another study showed that enforced let-7 expression depleted the self-renewing compartment through identification of miRNA signature in a population of purified self-renewing progenitor cells [108]. miR-205 and -22 were found to highly express in mammary progenitor cells, while let-7 and miR-93 were depleted. Further studies demonstrated that let-7 sensors could be used to prospectively enrich self-renewing populations, and that enforced let- 7 expression induced loss of self-renewing cells from mixed cultures. These 
results revealed a role for let-7 in regulating stemness, suggesting that miRNAs might play important roles in CSC proliferation, differentiation and tumor formation. Some miRNAs themselves are considered to be stem cell-like miRNAs recently. Cairo et al. [109] reported that undifferentiated aggressive hepatoblastoma (HBs) overexpressed the miR-371-3 cluster with concomitant down-regulation of the miR-100/let-7a-2/miR-125b-1 cluster. Their combined deregulation cooperated in modulating the hepatic tumor phenotype, implicating stem cell-like regulation of Myc-dependent miRNAs in poorly differentiated HBs. This important finding adds miRNAs as new role in tumor regulation.

\section{miRNAs and anticancer drug resistance}

Drug resistance remains a major clinical obstacle to successful treatment. The understanding of the drug resistance mechanism is important for the cancer therapy. Increasing evidence has indicated that aberrant miRNA expression is strongly implicated in anticancer drug resistance [110-112]. Significant overexpression of 8 miRNAs and down-regulation of 7 miRNAs were detected in a tamoxifen-resistant breast cancer cell line compared with the tamoxifen-sensitive cell line [113]. Kovalchuk et al. [114] reported that miR-451 regulated the expression of multidrug resistance 1 (MDR-1) gene in the doxorubicin-resistant human breast adenocarcinoma cell line MCF-7. In ovarian cancer, Yang et al. [115] demonstrated that the up-regulation of miR-214 promoted the survival of ovarian cancer cells and induced resistance of cisplatin. Sorrentino et al. [116] showed that a panel of miRNAs (let-7e, miR-30c, -125b, -130a and -335) were diversely expressed in all the resistant cell lines of ovarian cancer. In non-small cell lung cancer, 5 miRNAs (miR-15b, -100, -125b, -221, and -222) were found to up-regulate in the resistant cell lines [117]. Forced overexpression of the miR-222, -100, and -221 in the sensitive $\mathrm{H} 460$ cells increased resistance to TNF-related apoptosis inducing ligand (TRAIL), indicating that inhibition of their target proteins results in TRAIL resistance. Bertino et al. [118] put forward the concept of miRNA pharmacogenomics, a novel and promising field of research that holds new possibilities for medical therapy. This model can be defined as the study miRNAs and the miRSNPs/polymorphisms in their target genes may determine drug behavior in order to improve efficiency of drugs. Upon reaching a deeper understanding of the mechanism of miRNA in anticancer drug resistance, miRNAs might well fulfill their promise as valuable therapeutics in overcoming anticancer drug resistance.

\section{miRNAs related cancer diagnosis and therapy}

As the important roles of miRNAs in cancer are gradually revealed, their potential applications as useful and effective targets have generated great interest in cancer gene therapy strategies, as well as diagnosis, classification, prognosis and risk factor evaluations. Based on microarrays for miRNA expression profiling studies, differences in miRNA expression could be detected between normal and cancer tissues, which can classify different tumor types and tumor grades [119121]. Certain miRNA signatures are correlated with prognosis and can potentially be used to determine the specific course of treatment. Michael et al. [122] found aberrant miRNA expression in solid tumors as they identified 28 different miRNAs in colonic adenocarcinoma compared with normal mucosa. miR-143 and -145 were significantly down-regulated in the cancer. Similar situation was detected in other cancers, as miR-221, -222, and -146 in papillary thyroid carcinoma [123], miR-21 and -155 in pancreatic cancer [124], and miR-141 in prostate cancer [125]. Through analyzing the expression of 217 miRNAs in 334 samples that included primary tumors, tumor-derived cell lines and normal tissues, Lu et al. [16] found that miRNA profiles can distinguish between normal and cancer tissues, separate different cancer types, stratify the cancer differentiation state and cluster sample groups according to their embryonic lineage. Single nucleotide polymorphisms (SNPs) within the miRNA coding genes or within miRNA target genes are likely to be deleterious and can affect an individual's risk to develop diseases such as cancers. Yu et al. [126] found that 12 miRNA-related SNPs showed an aberrant allele frequency in human cancers. Chin et al. [127] identified an SNP in let-7 complementary site 6 (LCS6) in the KRAS 30 UTR that is associated with smoking-induced lung cancer risk. This variant allele is found in $20 \%$ of the 74 non-small cell lung carcinoma patients in the study. These unique miRNA expression signatures might be the hallmarks of tumor progressions and prognosis evaluations.

Many miRNAs, as discussed above, have great potential in tumorigenesis, tumor invasion, ametastasis, malignant progression, and poor prognosis. In in vitro and in vivo experiments, it has been confirmed that knockdown of certain miRNAs could change the tumor progression and biological characteristics as potential therapeutic targets [128-129]. In cell culture and xenograft mice models, synthetic anti-miRNA oligonucleotide (AMO) with 2'-O-methyl modification have been shown to effectively inhibit endogenous miRNAs. Krützfeldt et al. [130] studied the utility of AMOs in vivo through 
intravenous injection of modified AMOs to target the liver-specific miR-122. Impressively, a single injection of $240 \mathrm{mg} \cdot \mathrm{kg}^{-1}$ body weight conferred specific miR-122 silencing for up to 23 days. As an alternative to 2'-hydroxyl-modified AMOs, lock nucleic acid based oligonucleotides (LNA-antimiR) have been shown to be more stable and less toxic in inhibiting endogenous miRNAs in vivo. Kota et al. [131] showed that the systemic delivery of a single miRNA could cause tumor regression in a mice model of liver cancer. They delivered adeno-associated virus 8 (AAV8)-expressing miR-26a intravenously in Myc-induced mice harboring preformed liver tumors. After 3 weeks, they observed a significant regression of tumors in mice with the miR-26a treatment. These findings indicate a possibility of specific miRNAs-target therapy.

\section{Conclusion and perspective}

The importance of miRNAs in cancer has been well established and some special miRNAs have been regarded as hallmarks in tumor progressions and hot targets in cancer therapy. However, there is still a long and arduous way to go for substantial applications of miRNAs in cancer treatments. To date, the exact mechanisms and entire networks of miRNAs in cancer progressions are still unclear, and there is even some controversy about their roles in tumor regulation. For example, Ma et al. [52] reported that miR-9 acted as an oncogene and regulates the metastasis of lung cancer cell, while Wan et al. [132] suggested miR-9 as a tumor suppressive gene by targeting NF- $\kappa \mathrm{B}$ in gastric cancer; Similarly to miR-9, -107 and $-125 b$ function as oncogenes in some tumors and as a tumor-suppressor in others [133-138]. In OSCC, expression of miR-31 was reported to be up-regulated [139-140]. However, it appeared to down-regulation in gastric carcinoma and prostate carcinoma [141-142]. These results need to be further confirmed. It is also possible that the contradictory results implied regulation mechanisms uncovered in the relationships between miRNAs and cancers. One hypothesis is that certain miRNAs might have different roles in different tissues or different cancer types, or even there are some unknown molecules or genes regulating the same miRNAs to perform various roles in different situations. As a "star molecule" since 2002, miRNAs have become the focus in recent years and the studies of their roles in cancers have continued. In 2010, Guo et al. [143] found that changes in mRNA levels closely reflected the impact of miRNAs on gene expression, indicating that destabilization of target mRNAs was the predominant reason for reduced protein output. This means that miRNAs play their roles mainly by degrading the target mRNA $(\geq 84 \%$ lowered mRNA levels account for of the decreased protein production) rather than by inhibiting their translation. Meanwhile, Zhang et al. [144] reported that cells can secrete miRNAs and deliver them into recipient cells where the exogenous miRNAs can regulate target gene expression and recipient cell function as signaling molecules mediating intercellular communication. These results provide the potential mechanism of miRNAs in cancers, and indicate a novel approach for future research. Although our knowledge about the exact roles of miRNAs as well as their regulating genes in cancers is limited, we believe that the prospects of cancer research on miRNA field are broad.

\section{Acknowledgement}

We thank Xiao-wei Wang at Washington University in St. Louis for the proofreading. This work was supported by National Natural Science Foundation of China grants (No. 30872889, 81072215, 81001210, 81172580), by Scientific Research Foundation for the Returned Overseas Chinese Scholars, State Education Ministry (No. 20098-8-2) and by State Key Laboratory of Oral Diseases Open Funding (SKLODOF2010-05) and the Fundamental Research Funds of the Central Universities of China (2011).

\section{References}

1 Lee RC, Feinbaum RL, Ambros V. The C. elegans heterochronic gene lin-4 encodes small RNAs with antisense complementarity to lin-14. Cell 1993; 75: 843-854.

2 Wightman B, Ha I, Ruvkun G. Posttranscriptional regulation of the heterochronic gene lin-14 by lin-4 mediates temporal pattern formation in C. elegans. Cell 1993; 75: 855-862.

3 Bartel DP. MicroRNAs: genomics, biogenesis, mechanism, and function. Cell 2004; 116: 281-297.

4 Yi R, Qin Y, Macara IG, et al. Exportin-5 mediates the nuclear export of pre-microRNAs and short hairpin RNAs. Genes Dev 2003; 17: 3011-3016.

5 Lee Y, Ahn C, Han J, et al. The nuclear RNase III Drosha initiates microRNA processing. Nature 2003; 425: 415-419.

6 Diederichs S, Haber DA. Dual role for argonautes in microRNA processing and posttranscriptional regulation of microRNA expression. Cell 2007; 131: 1097-1108.

7 Lagos-Quintana M, Rauhut R, Meyer J, et al. New microRNAs from mouse and human. RNA 2003; 9:175-179.

8 Bernstein E, Kim SY, Carmell MA, et al. Dicer is essential for mouse development. Nat Genet 2003; 35: 215-217.

9 Alvarez-Garcia I, Miska EA. MicroRNA functions in animal 
development and human disease. Development 2005; 132: 4653-4662.

10 Bartel DP. MicroRNAs: target recognition and regulatory functions. Cell 2009; 136: 215-233.

11 Kloosterman WP, Plasterk RH. The diverse functions of microRNAs in animal development and disease. Dev Cell 2006; 11: 441-450.

12 Calin GA, Dumitru CD, Shimizu M, et al. Frequent deletions and down-regulation of microRNA genes miR15 and miR16 at 13q14 in chronic lymphocytic leukemia. Proc Natl Acad Sci U S A 2002; 99: 15524-15529.

13 Calin GA, Sevignani C, Dumitru CD, et al. Human microRNA genes are frequently located at fragile sites and genomic regions involved in cancers. Proc Natl Acad Sci U $S$ A 2004; 101: 2999-3004.

14 Calin GA, Croce CM. MicroRNA signatures in human cancers. Nat Rev Cancer 2006; 6: 857-866.

15 Gaur A, Jewell DA, Liang Y, et al. Characterization of microRNA expression levels and their biological correlates in human cancer cell lines. Cancer Res 2007; 67: 24562468.

16 Lu J, Getz G, Miska EA, et al. MicroRNA expression profiles classify human cancers. Nature 2005; 435: 834-838.

17 Sassen S, Miska EA, Caldas C. MicroRNA-implications for cancer. Virchow Archiv 2008; 452: 1-10.

18 Wiemer EA. The role of microRNAs in cancer: no small matter. Eur J Cancer 2007; 43: 1529-1544.

19 Hüsemann Y, Geigl JB, Schubert F, et al. Systemic spread is an early step in breast cancer. Cancer Cell 2008; 13: 58-68.

20 Liu X, Sempere LF, Ouyang H, et al. MicroRNA-31 functions as an oncogenic microRNA in mouse and human lung cancer cells by repressing specific tumor suppressors. $J$ Clin Invest 2010; 120: 1298-1309.

21 Sarver AL, Li L, Subramanian S. MicroRNA miR-183 functions as an oncogene by targeting the transcription factor EGR1 and promoting tumor cell migration. Cancer Res 2010; 70: 9570-9580.

22 Fang L, Deng Z, Shatseva T, et al. MicroRNA miR-93 promotes tumor growth and angiogenesis by targeting integrin- $\beta 8$. Oncogene 2010; 30: 806-821.

23 Diosdado B, van de Wiel MA, Terhaar Sive Droste JS, et al. MiR-17-92 cluster is associated with $13 \mathrm{q}$ gain and c-myc expression during colorectal adenoma to adenocarcinoma progression. Br J Cancer 2009; 101: 707-714.

24 Cloonan N, Brown MK, Steptoe AL, et al. The miR-17-5p microRNA is a key regulator of the G1/S phase cell cycle transition. Genome Biol 2008; 9: R127.

25 Petrocca F, Visone R, Onelli MR, et al. E2F1-regulated microRNAs impair TGF beta-dependent cell-cycle arrest and apoptosis in gastric cancer. Cancer Cell 2008; 13: 272-286.

26 Medina PP, Nolde M, Slack FJ. OncomiR addiction in an in vivo model of microRNA-21-induced pre-B-cell lymphoma.
Nature 2010; 467: 86-90.

27 Meng F, Henson R, Wehbe-Janek H, et al. MicroRNA-21 regulates expression of the PTEN tumor suppressor gene in human hepatocellular cancer. Gastroenterology 2007; 133: 647-658.

28 Volinia S, Calin GA, Liu CG, et al. A microRNA expression signature of human solid tumors defines cancer gene targets.

Proc Natl Acad Sci U S A 2006; 103: 2257-2261.

29 Ciafre SA, Galardi S, Mangiola A, et al. Extensive modulation of a set of microRNAs in primary glioblastoma. Biochem Biophys Res Commun 2005; 334: 1351-1358.

30 Li J, Huang H, Sun L, et al. MiR-21 indicates poor prognosis in tongue squamous cell carcinomas as an apoptosis inhibitor. Clin Cancer Res 2009; 15: 3998-4008.

31 Chang SS, Jiang WW, Smith I, et al. MicroRNA alterations in head and neck squamous cell carcinoma. Int J Cancer 2008; 123: 2791-2797.

32 Cervigne NK, Reis PP, Machado J, et al. Identification of a microRNA signature associated with progression of leukoplakia to oral carcinoma. Hum Mol Genet 2009; 18: 4818-4829.

33 Cimmino A, Calin GA, Fabbri M, et al. miR-15 and miR-16 induce apoptosis by targeting BCL2. Proc Natl Acad Sci U S A 2005; 102: 13944-13949.

34 Marcucci G, Mrózek K, Radmacher MD, et al. MicroRNA expression profiling in acute myeloid and chronic lymphocytic leukaemias. Best Pract Res Clin Heamatol 2009; 22: 239-248.

35 Kumar M, Erkeland S, Pester R, et al. Suppression of nonsmall cell lung tumor development by the let-7 microRNA family. Proc Natl Acad Sci U S A 2008; 105: 3903-3908.

36 Johnson SM, Grosshans H, Shingara J, et al. Ras is regulated by the let-7 microRNA family. Cell 2005; 120: 635-647.

37 Lee KH, Chen YL, Yeh SD, et al. MicroRNA-330 acts as tumor suppressor and induces apoptosis of prostate cancer cells through E2F1-mediated suppression of Akt phosphorylation. Oncogene 2009; 28: 3360-3370.

38 Welch C, Chen Y, Stallings RL. MicroRNA-34a functions as a potential tumor suppressor by inducing apoptosis in neuroblastoma cells. Oncogene 2007; 26: 5017-5022.

39 Carninci P, Kasukawa T, Katayama S, et al. The transcriptional landscape of the mammalian genome. Science 2005; 309: 1559-1563.

40 Katayama S, Tomaru Y, Kasukawa T, et al. Antisense transcription in the mammalian transcriptome. Science 2005; 309: 1564-1566.

41 Nomura, Katunuma N. Involvement of cathepsins in the invasion, metastasis and proliferation of cancer cells. $J$ Med Invest 2005; 52: 1-9.

42 Jeffers M, Rong S, Woude GF. Hepatocyte growth factor/ scatter factor-Met signaling in tumorigenicity and invasion/ 
metastasis. J Mol Med 1996; 74: 505-513.

43 Cano A, Pérez-Moreno MA, Rodrigo I, et al. The transcription factor snail controls epithelial-mesenchymal transitions by repressing E-cadherin expression. Nat Cell Biol 2000; 2: 76-83.

44 Comijn J, Berx G, Vermasen P, et al. The two-handed E box binding zinc finger protein SIP1 downregulates E-cadherin and induces invasion. Mol Cell 2001; 7: 1267-1278.

45 Bremnes RM, Veve R, Hirsch FR, et al. The E-cadherin cell-cell adhesion complex and lung cancer invasion, metastasis, and prognosis. Lung Cancer 2002; 36: 115-124.

46 Masterson J, O'Dea S. Posttranslational truncation of E-cadherin and significance for tumour progression. Cells Tissues Organs 2007; 185: 175-179.

47 Place RF, Li LC, Pookot D, et al. MicroRNA-373 induces expression of genes with complementary promoter sequences. Proc Natl Acad Sci U S A 2008; 105: 1608-1613.

48 Ma L, Weinberg RA. Micromanagers of malignancy: role of microRNAs in regulating metastasis. Trends Genet 2008; 24 448-456.

49 Huang Q, Gumireddy K, Schrier M, et al. The microRNAs miR-373 and miR-520c romote tumour invasion and metastasis. Nat Cell Biol 2008; 10: 202-210.

50 Voorhoeve PM, le Sage C, Schrier M, et al. A genetic screen implicates miRNA-372 and miRNA-373 as oncogenes in testicular germ cell tumors. Cell 2006; 124: 1169-1181.

51 Ma L, Teruya-Feldstein J, Weinberg RA. Tumour invasion and metastasis initiated by microRNA-10b in breast cancer. Nature 2007; 449: 682-688.

52 Ma L, Young J, Prabhala H, et al. miR-9, a MYC/MYCNactivated microRNA, regulates E-cadherin and cancer metastasis. Nat Cell Biol 2010; 12: 247-256.

53 Chan JA, Krichesky AM, Kosik KS. MicroRNA-21 is an antiapoptotic factor in human glioblastoma cells. Cancer Res 2005; 65: 6029-6033.

54 Si ML, Zhu S, Wu H, et al. miR-21-mediated tumor growth. Oncogene 2007; 26: 2799-2803.

55 Zhu S, Si ML, Wu H, et al. MicroRNA-21 targets the tumor suppressor gene tropomyosin 1 (TPM1). J Biol Chem 2007; 282: $14328-14336$.

56 Zhu S, Wu H, Wu F, et al. MicroRNA-21 targets tumor suppressor genes in invasion and metastasis. Cell Res 2008; 18: $350-359$.

57 Asangani IA, Rasheed SA, Nikolova DA, et al. MicroRNA-21 (miR-21) post-transcriptionally downregulates tumor suppressor Pdcd4 and stimulates invasion, intravasation and metastasis in colorectal cancer. Oncogene 2008; 27: 2128 2136.

58 Mayr C, Hemann MT, Bartel DP. Disrupting the pairing between let-7 and Hmga2 enhances oncogenic transformation. Science 2007; 315: 1576-1579.

59 Park SM, Shell S, Radjabi AR, et al. Let-7 prevents early cancer progression by suppressing expression of the embryonic gene HMGA2. Cell Cycle 2007; 6: 2585-2590.

60 Lee YS, Dutta A. The tumor suppressor microRNA let-7 represses the HMGA2 oncogene. Genes Dev 2007; 21: $1025-1030$

61 Park SM, Gaur AB, Lengyel E, et al. The miR-200 family determines the epithelial phenotype of cancer cells by targeting the E-cadherin repressors ZEB1 and ZEB2. Genes Dev 2008; 22: 894-907.

62 Martello G, Rosato A, Ferrari F, et al. A MicroRNA targeting dicer for metastasis control. Cell 2010; 141: 1195 1207.

63 Burk U, Schubert J, Wellner U, et al. A reciprocal repression between ZEB1 and members of the miR-200 family promotes EMT and invasion in cancer cells. EMBO Rep 2008; 9: 582-589.

64 Korpal M, Lee ES, Hu G, et al. The miR-200 family inhibits epithelial-mesenchymal transition and cancer cell migration by direct targeting of E-cadherin transcriptional repressors ZEB1 and ZEB2. J Biol Chem 2008; 283: 14910-14914.

65 Katoh M. Networking of WNT, FGF, Notch, BMP, and Hedgehog signaling pathways during carcinogenesis. Stem Cell Rev 2007; 3: 30-38.

66 Thiery JP. Epithelial-mesenchymal transitions in tumour progression. Nature Rev Cancer 2002; 2: 442-454.

67 Gregory PA, Bert AG, Paterson EL, et al. The miR-200 family and miR-205 regulate epithelial to mesenchymal transition by targeting ZEB1 and SIP1. Nat Cell Biol 2008; 10: 593-601.

68 van den Brink GR, Bleuming SA, Hardwick JC, et al. Indian Hedgehog is an antagonist of Wnt signaling in colonic epithelial cell differentiation. Nat Genet 2004; 36: 277-282.

69 Kerbel RS. Tumor angiogenesis. N Engl J Med 2008; 358: 2039-2049.

70 Urbich C, Kuehbacher A, Dimmeler S. Role of microRNAs in vascular diseases, inflammation, and angiogenesis. Cardiovasc Res 2008; 79: 581-588.

71 Fish JE, Santoro MM, Morton SU, et al. miR-126 regulates angiogenic signaling and vascular integrity. Dev Cell 2008; 15: 272-284.

72 Wang S, Aurora AB, Johnson BA, et al. The endothelialspecific microRNA miR-126 governs vascular integrity and angiogenesis. Dev Cell 2008; 15: 261-271.

73 Nicoli S, Standley C, Walker P, et al. MicroRNA-mediated integration of haemodynamics and Vegf signalling during angiogenesis. Nature 2010; 464: 1196-1200.

74 Sun Y, Bai Y, Zhang F, et al. miR-126 inhibits non-small cell lung cancer cells proliferation by targeting EGFL7. Biochem Biophys Res Commun 2009; 391: 1483-1489.

75 Tavazoie SF, Alarcón C, Oskarsson T, et al. Endogenous human microRNAs that suppress breast cancer metastasis. Nature 2008; 451: 147-152. 
76 Budhu A, Jia HL, Forgues M, et al. Identification of metastasis-related microRNAs in hepatocellular carcinoma. Hepatology 2008; 47: 897-907.

77 Hussain SP, Harris CC. Inflammation and cancer: an ancient link with novel potentials. Int J Cancer 2007; 121: 23732380.

78 Mantovani A, Romero P, Palucka AK, et al. Tumour immunity: effector response to tumour and role of the microenvironment. Lancet 2008; 371: 771-783.

79 Medzhitov R. Origin and physiological roles of inflammation. Nature 2008; 454: 428-435.

80 Xiao C, Rajewsky K. MicroRNA control in the immune system: basic principles. Cell 2009; 136: 26-36.

81 Taganov KD, Boldin MP, Chang KJ, et al. NF-kappaBdependent induction of microRNA miR-146, an inhibitor targeted to signaling proteins of innate immune responses. Proc Natl Acad Sci U S A 2006; 103: 12481-12486.

82 Perry MM, Moschos SA, Williams AE, et al. Rapid changes in microRNA-146a expression negatively regulate the IL-1beta-induced inflammatory response in human lung alveolar epithelial cells. J Immunol 2008; 180: 5689-5698.

$83 \mathrm{Wu}$ H, Neilson JR, Kumar P, et al. miRNA profiling of naive, effector and memory CD8 T cells. PLoS ONE 2007; 2: e1020.

84 Moschos SA, Williams AE, Perry MM, et al. Expression profiling in vivo demonstrates rapid changes in lung microRNA levels following lipopolysaccharide-induced inflammation but not in the anti-inflammatory action of glucocorticoids. BMC Genomics 2007; 8: 240.

85 Lu TX, Munitz A, Rothenberg ME. microRNA-21 is upregulated in allergic airway inflammation and regulates IL-12p35 expression. J Immunol 2009; 182: 4994-5002.

86 Schetter AJ, Nguyen GH, Bowman ED, et al. Association of inflammation-related and microRNA gene expression with cancer-specific mortality of colon adenocarcinoma. Clin Cancer Res 2009; 15: 5878-5887.

87 Rodriguez A, Vigorito E, Clare S, et al. Requirement of bic/microRNA-155 for normal immune function. Science 2007; 316: 608-611.

88 Moffett HF, Novina CD. A small microRNA makes a Bic difference. Genome Biol 2007; 8: 221.

89 Thai TH, Calado DP, Casola S, et al. Regulation of the germinal center response by microRNA-155. Science 2007; 316: 604-607.

90 O'Connell RM, Taganov KD, Boldin MP, et al. microRNA-155 is induced during the macrophage inflammatory response. Proc Natl Acad Sci USA 2007; 104: 1604-1609.

91 Tili E, Michaille JJ, Cimino A, et al. Modulation of miR-155 and miR-125b levels following lipopolysaccharide/TNF-alpha stimulation and their possible roles in regulating the response to endotoxin shock. J Immunol 2007; 179: 5082-
5089.

92 Gironella M, Seux M, Xie MJ, et al. Tumor protein 53 -induced nuclear protein 1 expression is repressed by miR-155, and its restoration inhibits pancreatic tumor development. Proc Natl Acad Sci U S A 2007; 104: 16170 16175.

93 Hayashita Y, Osada H, Tatematsu Y, et al. A polycistronic microRNA cluster, miR-17-92, is overexpressed in human lung cancers and enhances cell proliferation. Cancer Res 2005; 65: 9628-9632.

94 Mendell JT. miRiad roles for the miR-17-92 cluster in development and disease. Cell 2008; 133: 217-222.

95 Fontana L, Pelosi E, Greco P, et al. microRNAs 17-5p-20a106a control monocytopoiesis through AML1 targeting and M-CSF receptor upregulation. Nat Cell Biol 2007; 9: 775787.

96 Iliopoulos D, Hirsch HA, Struhl K. An epigenetic switch involving NF-kappaB, Lin28, Let-7 MicroRNA, and IL6 links inflammation to cell transformation. Cell 2009; 139: 693-706.

97 Sonkoly E, Pivarcsi A. microRNAs in inflammation. Int Rev Immunol 2009; 28: 535-561.

98 Bazzoni F, Rossato M, Fabbri M, et al. Induction and regulatory function of miR-9 in human monocytes and neutrophils exposed to proinflammatory signals. Proc Natl Acad Sci U S A 2009; 106: 5282-5287.

$99 \mathrm{Yu} \mathrm{Z}, \mathrm{Li} \mathrm{Z}$, Jolicoeur N, et al. Aberrant allele frequencies of the SNPs located in microRNA target sites are potentially associated with human cancers. Nucleic Acids Res 2007; 35: 4535-4541.

100 Braun CJ, Zhang X, Savelyeva I, et al. p53-Responsive microRNAs 192 and 215 are capable of inducing cell cycle arrest. Cancer Res 2008; 68: 10094-10104.

101 Lena AM, Shalom-Feuerstein R, Rivetti di Val Cervo P, et al. miR-203 represses 'stemness' by repressing DeltaNp63. Cell Death Differ 2008; 15: 1187-1195.

102 Schetter AJ, Heegaard NH, Harris CC. Inflammation and cancer: interweaving microRNA, free radical, cytokine and p53 pathways. Carcinogenesis 2010; 31: 37-49.

103 Wicha MS, Liu S, Dontu G. Cancer stem cells: an old idea a paradigm shift. Cancer Res 2006; 66: 1883-1890.

104 Al-Hajj M, Becker MW, Wicha M, et al. Therapeutic implications of cancer stem cells. Curr Opin Genet Dev 2004; 14: 43-47.

105 Clarke MF, Dick JE, Dirks PB, et al. Cancer stem cells perspectives on current status and future directions: AACR workshop on cancer stem cells. Cancer Res 2006; 66: 9339-9344.

106 Collins AT, Berry PA, Hyde C, et al. Prospective identification of tumorigenic prostate cancer stem cells. Cancer Res 2005; 65: 10946-10951.

107 Yu D, Tan AH, Hu X, et al. Roquin represses autoimmunity 
by limiting inducible T-cell co-stimulator messenger RNA. Nature 2007; 450: 299-303.

108 Ibarra I, Erlich Y, Muthuswamy SK, et al. A role for microRNAs in maintenance of mouse mammary epithelial progenitor cells. Genes Dev 2007; 21: 3238-3243.

109 Cairo S, Wang Y, de Reynièse A, et al. Stem cell-like micro-RNA signature driven by Myc in aggressive liver cancer. Proc Natl Acad Sci U S A 2010; 107: 20471-20476.

110 Szakacs G, Paterson JK, Booth-Genthe C, et al. Targeting multidrug resistance in cancer. Nat Rev Drug Discov 2006; 5 219-234.

111 Iwasa Y, Nowak MA, Michor F. Evolution of resistance during clonal expansion. Genetics 2006; 172: 2557-2566.

112 Duesberg P, Li R, Sachs R, et al. Cancer drug resistance: the central role of the karyotype. Drug Resist Updat 2007; 10: 51-58.

113 Miller TE, Ghoshal K, Ramaswamy B, et al. MicroRNA-221/ 222 confers tamoxifen resistance in breast cancer by targeting p27 (Kip1). J Biol Chem 2008; 283: 29897-29903.

114 Kovalchuk O, Filkowski J, Meservy J, et al. Involvement of microRNA-451 in resistance of the MCF-7 breast cancer cells to chemotherapeutic drug doxorubicin. Mol Cancer Ther 2008; 7: 2152-2159.

115 Yang H, Kong W, He L, et al. MicroRNA expression profiling in human ovarian cancer: miR-214 induces cell survival and cisplatin resistance by targeting PTEN. Cancer Res 2008; 68: 425-433.

116 Sorrentino A, Liu CG, Addario A, et al. Role of microRNAs in drug-resistant ovarian cancer cells. Gynecol Oncol 2008; 111: 478-486.

117 Garofalo M, Quintavalle C, Di Leva G, et al. MicroRNA signatures of TRAIL resistance in human non-small cell lung cancer. Oncogene 2008; 27: 3845-3855.

118 Bertino JR, Banerjee D, Mishra PJ. Pharmacogenomics of microRNA: a miRSNP towards individualized therapy. Pharmacogenomics 2007; 8: 1625-1627.

119 Visone R, Pallante P, Vecchione A, et al. Specific microRNAs are downregulated in human thyroid anaplastic carcinomas. Oncogene 2007; 26: 7590-7595.

120 Yanaihara N, Caplen N, Bowman E, et al. Unique microRNA molecular profiles in lung cancer diagnosis and prognosis. Cancer Cell 2006; 9: 189-198.

121 Trang P, Weidhaas JB, Slack FJ. MicroRNAs as potential cancer therapeutics. Oncogene 2008; 27: S52-S57.

122 Michael MZ, O'Connor SM, van Holst Pellekaan NG, et al. Reduced accumulation of specific microRNAs in colorectal neoplasia. Mol Cancer Res 2003; 1: 882-891.

123 He H, Jazdzewski K, Li W, et al. The role of microRNA genes in papillary thyroid carcinoma. Proc Natl Acad Sci U S A 2005; 102: 19075-19080.

124 Bloomston M, Frankel WL, Petrocca F, et al. MicroRNA expression patterns to differentiate pancreatic adenocar- cinoma from normal pancreas and chronic pancreatitis. JAMA 2007; 297: 1901-1908.

125 Mitchell PS, Parkin RK, Kroh EM, et al. Circulating microRNAs as stable blood-based markers for cancer detection. Proc Natl Acad Sci U S A 2008; 105: 10513-10518.

126 Yu F, Yao H, Zhu P, et al. let-7 regulates self renewal and tumorigenicity of breast cancer cells. Cell 2007; 131: 1109 1123.

127 Chin LJ, Ratner E, Leng S, et al. A SNP in a let-7 microRNA complementary site in the KRAS 30 untranslated region increases non-small cell lung cancer risk. Cancer Res 2008; 68: 8535-8540.

128 Bonci D, Coppola V, Musumeci M, et al. The miR-15amiR-16-1 cluster controls prostate cancer by targeting multiple oncogenic activities. Nat Med 2008; 14: 12711277.

129 Jackson EL, Willis N, Mercer K, et al. Analysis of lung tumor initiation and progression using conditional expression of oncogenic K-ras. Genes Dev 2001; 15: 3243-3248.

130 Krützfeldt J, Rajewsky N, Braich R, et al. Silencing of microRNAs in vivo with 'antagomirs'. Nature 2005; 438 : 685-689.

131 Kota J, Chivukula RR, O'Donnell KA, et al. Therapeutic microRNA delivery suppresses tumorigenesis in a murine liver cancer model. Cell 2009; 137: 1005-1017.

132 Wan H, Guo L, Liu T, et al. Regulation of the transcription factor NF- $\mathrm{BB} 1$ by microRNA-9 in human gastric adenocarcinoma. Mol Cancer 2010; 9: 16.

133 Yamakuchi M, Lotterman CD, Bao C, et al. P53-induced microRNA-107 inhibits HIF-1 and tumor angiogenesis. Proc Natl Acad Sci U S A 2010; 107: 6334-6339.

134 Li X, Zhang Y, Shi Y, et al. MicroRNA-107, an oncogene microRNA that regulates tumor invasion and metastasis by targeting DICER1 in gastric cancer: miR-107 promotes gastric cancer invasion and metastasis. J Cell Mol Med 2010 Oct 3. doi: 10.1111/j.1582-4934.2010.01194.x

135 Scott GK, Goga A, Bhaumik D, et al. Coordinate suppression of ERBB2 and ERBB3 by enforced expression of micro-RNA miR-125a or miR-125b. J Biol Chem 2007; 282: 1479-1486.

136 Shi XB, Xue L, Yang J, et al. An androgen-regulated miRNA suppresses Bak1 expression and induces androgenindependent growth of prostate cancer cells. Proc Natl Acad Sci U S A 2007; 104: 19983-19988.

137 Iorio MV, Ferracin M, Liu CG, et al. microRNA gene expression deregulation in human breast cancer. Cancer Res 2005; 65: 7065-7070.

138 Nagayama K, Kohno T, Sato M, et al. Homozygous deletion scanning of the lung cancer genome at a $100-\mathrm{kb}$ resolution. Genes Chromosomes Canc 2007; 46: 1000-1010.

139 Kozaki K, Imoto I, Mogi S, et al. Exploration of tumorsuppressive microRNAs silenced by DNA hypermethylation 
in oral cancer. Cancer Res 2008; 68: 2094-2105.

140 Wong TS, Liu XB, Wong BY, et al. Mature miR-184 as potential oncogenic microRNA of squamous cell carcinoma of tongue. Clin Cancer Res 2008; 14: 2588-2592.

141 Zhang Y, Guo J, Li D, et al. Down-regulation of miR-31 expression in gastric cancer tissues and its clinical significance. Med Oncol 2010; 27: 685-589.

142 Schaefer A, Jung M, Mollenkopf HJ, et al. Diagnostic and prognostic implications of microRNA profiling in prostate carcinoma. Int J Cancer 2010; 126: 1166-1176.

143 Guo H, Ingolia NT, Weissman JS, et al. Mammalian microRNAs predominantly act to decrease target mRNA levels. Nature 2010; 466: 835-841.

144 Zhang Y, Liu D, Chen X, et al. Secreted monocytic miR-150 enhances targeted endothelial cell migration. Mol Cell 2010; 39: $133-144$ 